\title{
MOMENTOS PEDAGÓGICOS E AS ETAPAS DA SITUAÇÃO DE ESTUDO: COMPLEMENTARIDADES E CONTRIBUIÇÕES PARA A EDUCAÇÃO EM CIÊNCIAS
}

\section{Pedagogical moments and the stages of Study Situation: complementarities and contributions to the Science Education}

\author{
Simoni Tormöhlen Gehlen ${ }^{1}$ • Otavio Aloisio Maldaner ${ }^{2}$. \\ Demétrio Delizoicov ${ }^{3}$
}

\begin{abstract}
Resumo: Parte da pesquisa em Educação em Ciências tem se apoiado de forma significativa nas ideias de Freire e Vygotsky para configurar novas propostas curriculares. Destacam-se as propostas abordagem temática freireana e Situação de Estudo, balizadas, respectivamente, pelos pressupostos de Freire e Vygotsky. O objetivo deste trabalho consiste em analisar o processo de desenvolvimento das propostas em sala de aula, em que a abordagem temática freireana tem como base os momentos pedagógicos, enquanto a Situação de Estudo também apresenta determinadas etapas. Sinaliza-se que há complementaridade entre as propostas, em que as etapas da Situação de Estudo - problematização, primeira elaboração, função da elaboração e compreensão conceitual - , que configuram o processo da significação conceitual, contribuem no contexto dos momentos pedagógicos, uma vez que a organização do conbecimento pode ser potencializada seguindo as etapas da significação conceitual abordadas pela Situação de Estudo.
\end{abstract}

Palavras-chave: Situação de Estudo. Abordagem Temática Freireana. Paulo Freire. Vygotsky.

\begin{abstract}
Part of the research in Science Education has relied significantly on the ideas of Freire and Vygotsky to set new curriculum proposals. We highlight the proposals of a Freirean Thematic Approach and Study Situation, respectively by the ideas of Freire and Vygotsky. The objective of this study is to analyze the process of developing the proposals in the classroom, where Freirean Thematic Approach is based on Pedagogical Moments, and the Study Situation also has certain steps. It signals that there is complementarity between the proposals in the steps of the Study Situation - Problematization, First Establishment, Function of the Elaboration and Conceptual Understanding - which shape the process of conceptual meaning, contribute in the context of the Pedagogical Moments, since the Organization of Knowledge can be increased by following the steps of the conceptual significance addressed by the Study Situation.
\end{abstract}

Keywords: Study Situation. Freirean Thematic Approach. Freire, Paulo. Vygotsky, L. S.

\footnotetext{
${ }^{1}$ Departamento de Ciências Exatas e Tecnológicas, Universidade Estadual de Santa Cruz (UESC). Campus Soane Nazaré de Andrade, Km 16. Rodovia Ilhéus-Itabuna. Ilhéus, BA, Brasil.

45.662-900. simonigehlen@yahoo.com.br

2 Programa de Pós-Graduação em Educação nas Ciências, Universidade Regional do Noroeste do Estado do Rio Grande do Sul. Ijuí, RS, Brasil.

${ }^{3}$ Programa de Pós-Graduação em Educação Científica e Tecnológica, Universidade Federal de Santa Catarina. Florianópolis, SC, Brasil.
} 


\section{Introdução}

No ensino de Ciências existe uma preocupação cada vez mais significativa em torno da reestruturação curricular em que diversas propostas, em fase de elaboração e desenvolvimento, estão sendo acompanhadas pela pesquisa. Nessas propostas, há uma abordagem às diversas classes de problema, tais como: a) problemas sociais marcados pela dimensão científica e tecnológica ligados aos pressupostos do movimento Ciência-Tecnologia-Sociedade (CTS), como os estudos de Santos (2008), Auler et al. (2005), Andrade e Carvalho (2002) e Zylbersztajn e Cruz (2001); b) o problema como situações que envolvem questões sociais vivenciadas pela sociedade e comunidade escolar, representadas pelos temas transversais sugeridos pelos Parâmetros Curriculares Nacionais (BRASIL, 1997), e c) o problema como situações que envolvem o contexto do estudante e que auxiliam na estruturação de conceitos de uma determinada disciplina, a exemplo da proposta curricular do estado de Minas Gerais, que aborda determinados conteúdos de química por meio de temas (MORTIMER; MACHADO; ROMANELLI, 2000).

Há, também, propostas curriculares que se apoiam nas ideias de Paulo Freire, em que o problema assume papel fundamental na organização curricular, potencializando o processo de ensino-aprendizagem, como os estudos que exploram a abordagem temática freireana (DELIZOICOV, 1982, 1991, 2008; SILVA, 2004; DELIZOICOV; ANGOTTI; PERNAMBUCO, 2002; PONTUSCHKA, 1993; PERNAMBUCO, 1994; ANGOTTI, 1982). Assim como existem os trabalhos balizados pelos pressupostos de Vygotsky, em que o problema tem relação com as situações relacionadas à alta vivência dos estudantes fecundadas na significação de conceitos disciplinares e interdisciplinares das Ciências Naturais, denominadas de Situação de Estudo (MALDANER, 2007a; AUTH et al., 2004; MALDANER; ZANON, 2004).

$\mathrm{Na}$ Situação de Estudo não há aprofundamento, de forma dinâmica, do processo pedagógico em torno do seu desenvolvimento em sala de aula, como ocorre na abordagem temática freireana, por meio dos momentos pedagógicos (DELIZOICOV, 1991, 2008; DELIZOICOV; ANGOTTI; PERNAMBUCO, 2002), pois parece privilegiar a questão da significação conceitual, indicando preocupação mais cognitiva do que pedagógica. Desse modo, as etapas da Situação de Estudo serão explicitadas e aprofundadas, no sentido de se investigarem também complementaridades com os momentos pedagógicos. Com isso, o objetivo deste trabalho consiste em analisar o processo de desenvolvimento das propostas em sala de aula, que, na abordagem temática freireana, segue a dinâmica dos momentos pedagógicos (DELIZOICOV, 1991, 2008; DELIZOICOV; ANGOTTI; PERNAMBUCO, 2002), especificamente ancorada numa abordagem pedagógica; e na Situação de Estudo que, fundamentada na abordagem vygotskyana, apresenta uma sustentação teórica do ponto de vista cognitivo e também segue uma dinâmica específica sistematizada em três etapas.

Com base em pesquisas sobre aproximações teóricas entre Freire e Vygotsky, no que diz respeito a propostas curriculares na educação escolar, pode-se compreender melhor as possíveis complementaridades entre elas se as analisarmos, sob o ponto de vista teórico, em seus momentos e etapas, conforme explicitam os trabalhos de Gehlen (2009) e Gehlen et al. (2008).

Ciência \&̊̊ Educacão, v. 18, n. 1, p. 1-22, 2012 


\section{Momentos pedagógicos e as etapas da Situação de Estudo}

A estruturação da abordagem temática freireana contempla a investigação temática ${ }^{4}$ proposta por Freire (1987), a qual pode apresentar sintonia com alguns elementos da Situação de Estudo balizada pelas ideias vygotskyanas. Para discutir a possível sintonia entre as propostas, fez-se uso do processo de desenvolvimento dessas em sala de aula, uma vez que as etapas da elaboração e sistematização de uma Situação de Estudo não são explicitadas da mesma forma que na abordagem temática freireana. Isto é, na Situação de Estudo, não está explícito o processo de obtenção dos temas a serem abordados no contexto escolar, o que difere da abordagem temática freireana em que a investigação temática (FREIRE, 1987) se constitui na dinâmica para a obtenção dos temas a serem desenvolvidos.

\section{Problematização}

$\mathrm{Na}$ dinâmica dos momentos pedagógicos, organizada por Delizoicov $(1991,2008) \mathrm{e}$ por Delizoicov, Angotti e Pernambuco (2002), a problematização inicial caracteriza-se por apresentar situações reais que os alunos conhecem e vivenciam. É nesse momento que os estudantes são desafiados a expor os seus entendimentos sobre determinadas situações significativas que são manifestações de contradições locais (FREIRE, 1987) e que fazem parte de suas vivências. Vale lembrar que essas situações foram obtidas durante o processo de investigação temática e, portanto, estão diretamente vinculadas aos temas selecionados.

O trabalho de Silva (2004) ilustra as diversas questões desafiadoras que caracterizam a problematização inicial, denominadas, pelo autor, de estudo da realidade (ER), com o propósito de obter um panorama da concepção dos alunos acerca de aspectos que fazem parte do contexto em que vivem. Por exemplo, no Quadro 1, o tema "Falta d'água em AmericanópolisSP", a problematização inicial gira em torno de questões como: "Quais os equipamentos hidráulicos de sua casa? Como funcionam?", "Para onde vai a água utilizada em sua casa? Ela poderia ser reutilizada? Como?" e "Qual o consumo de água em sua casa? E no seu bairro?"

Segundo Delizoicov, Angotti e Pernambuco (2002), a finalidade da problematização inicial é propiciar um distanciamento crítico do aluno ao se defrontar com as interpretações das situações propostas para discussão e fazer com que ele reconheça a necessidade de se obterem novos conhecimentos, com os quais possa interpretar a situação mais adequadamente. Isto é: "[...] deseja-se aguçar explicações contraditórias e localizar as possíveis limitações do conhecimento que vem sendo expressado, quando este é cotejado com o conbecimento científico que já foi selecionado para ser abordado" (DELIZOICOV; ANGOTTI; PERNAMBUCO, 2002, p. 201).

\footnotetext{
${ }^{4}$ Sistematizado por Delizoicov $(1991,2008)$ em cinco etapas, a partir da proposição apresentada no capítulo 3 do livro Pedagogia do Oprimido (FREIRE, 1987): Primeira (levantamento preliminar): reconhecer o ambiente em que vive o aluno. Segunda (análise das situações e escolba das codificações): escolha de situações que sintetizam as contradições vividas. Terceira (diálogos descodificadores): a partir desses diálogos se obtêm os Temas Geradores. Quarta (redução temática): trabalho de uma equipe interdisciplinar, com o objetivo de elaborar o programa e identificar quais conhecimentos disciplinares são necessários para o entendimento dos temas. Quinta (trabalho em sala de aula): desenvolvimento do programa em sala de aula.
} 
Gehlen, S. T.; Maldaner, O. A.; Delizoicov, D.

Quadro 1. Organização do conteúdo programático por meio de Temas

\begin{tabular}{|c|c|c|}
\hline \multicolumn{3}{|c|}{ PROGRAMAÇÃO - CIÊNCIAS - 6a SÉRIE - FALTA D’ÁGUA EM AMERICANÓPOLIS - SP } \\
\hline $\begin{array}{l}\text { BLOCOS: } \\
\text { Tópicos } \\
\text { programáticos }\end{array}$ & & $\begin{array}{l}\text { FALAS X ATIVIDADES } \\
\text { (ORGANIZAÇÃO METODOLÓGICA) }\end{array}$ \\
\hline \multirow{4}{*}{$\begin{array}{l}\text { I Da pia } \\
\text { para outros } \\
\text { equipamentos } \\
\text { hidráulicos }\end{array}$} & Fala 2: & $\begin{array}{l}\text { Quando falta água, a ordem em que acaba nos equipamentos da residência } \\
\text { (tanques, pias, bacias etc) varia de casa para casa }\end{array}$ \\
\hline & $\mathrm{ER}$ * & Quais os equipamentos hidráulicos de sua casa? Como funcionam? \\
\hline & $O C$ * & $\begin{array}{l}\text { Classificando os equipamentos hidráulicos } \\
\text { Pia como um sistema - funcionamento de uma torneira: alavanca, torque, } \\
\text { pressão, rosca e ação e reação } \\
\text {. Funções: cano, bacia e ralo - abrindo e fechando o sistema }\end{array}$ \\
\hline & $A C^{*}$ & Extrapolando para outros equipamentos hidráulicos \\
\hline \multirow{4}{*}{$\begin{array}{l}\text { Il Da caixa } \\
\text { de descarga } \\
\text { para a caixa } \\
\text { d'água }\end{array}$} & Fala 2: & $\begin{array}{l}\text { Quando falta água, a ordem em que acaba nos equipamentos da residência } \\
\text { (tanques, pias, bacias etc) varia de casa para casa }\end{array}$ \\
\hline & ER & Como funciona a caixa de descarga? \\
\hline & OC & Sifão e bóia: vasos comunicantes, empuxo e feed-back negativo \\
\hline & $\mathrm{AC}$ & Reservatórios de água \\
\hline \multirow{4}{*}{$\begin{array}{l}\text { III Distribuição } \\
\text { da água: da } \\
\text { casa para o } \\
\text { bairro }\end{array}$} & $\underline{\text { Fala } 4 .}$ & $\begin{array}{l}\text { A água acaba sempre antes em algumas casas e deois em outras. Nem sempre } \\
\text { acaba a água em todas as regiões do bairro; há regiões onde a falta é mais } \\
\text { frequente }\end{array}$ \\
\hline & ER & $\begin{array}{l}\text { Aágua apresenta a mesma pressão em todos os equipamentos hidráulicos da } \\
\text { casa? Quando ocorrem vazamentos? }\end{array}$ \\
\hline & $\mathrm{OC}$ & $\begin{array}{l}\text { Relações entre os equipamentos hidráulicos de uma casa } \\
\text {. Vazamentos no sistema (desequilíbrios e conservações) }\end{array}$ \\
\hline & $\mathrm{AC}$ & Distribuição da água no bairro \\
\hline \multirow{4}{*}{$\begin{array}{l}\text { IV Estação de } \\
\text { tratamento de } \\
\text { água }\end{array}$} & Fala 3: & Após a falta de água, ela chega esbranquiçada e com cheiro desagradável \\
\hline & ER & $\begin{array}{l}\text { Que usos fazemos da água? Quando podemos considerar a água como de boa } \\
\text { qualidade para o consumo? }\end{array}$ \\
\hline & OC & $\begin{array}{l}\text { Propriedades físico-químicas da água: solubilidade, miscibilidade, densidade etc } \\
\text { - Fracionamento de misturas - Utilização da água pelos seres vivos }\end{array}$ \\
\hline & $\mathrm{AC}$ & Estação de tratamento de água \\
\hline \multirow{3}{*}{$\begin{array}{l}\text { V Consumo } \\
\text { de água } \\
\text { (homem) }\end{array}$} & ER & Qual o consumo de água em sua casa? E no seu bairro? \\
\hline & OC & . Leitura do hidrômetro; Cálculo do consumo médio e controle \\
\hline & $A C$ & . Consumo total de água na cidade (estimativa) \\
\hline
\end{tabular}

continua 
Momentos pedagógicos e as etapas ...

\begin{tabular}{|c|c|c|}
\hline \multicolumn{3}{|c|}{ Quadro 1. continuação } \\
\hline \multirow{4}{*}{$\begin{array}{l}\text { VI Estação de } \\
\text { tratamento de } \\
\text { esgoto; } \\
\text { Represa-ciclo } \\
\text { da água na } \\
\text { natureza }\end{array}$} & Fala 6: & A falta de chuva é uma fatalidade; quando há estiagem sempre falta água \\
\hline & ER & Para onde vai a água utlizada em sua casa? Ela poderia ser reutilizada? Como? \\
\hline & OC & $\begin{array}{l}\text { Sistema de coleta de esgoto } \\
\text {. Esgoto doméstico e industrial } \\
\text {. Coleta parcial: perda na captação } \\
\text {. Fontes fornecedoras: Mananciais }\end{array}$ \\
\hline & AC & . Ciclo da água (natureza): calor e clima como fatores reguladores \\
\hline \multirow{4}{*}{$\begin{array}{l}\text { VII } \\
\text { Distribuição } \\
\text { social da água } \\
\text { - visão geral do } \\
\text { processo e } \\
\text { extrapolações } \\
\text { para o planeta }\end{array}$} & Fala 7: & Mesmo nos períodos chuvosos há falta de água \\
\hline & $\begin{array}{l}\text { ER } \\
\text { OC }\end{array}$ & $\begin{array}{l}\text { O que há de comum entre o funcionamento de um equipamento hidráulico e a } \\
\text { distribuição da água urbana? Quais são os fatores reguladores nos dois níveis? } \\
\text { Só a falta de chuva explica o abastecimento precário em alguns bairros? }\end{array}$ \\
\hline & & $\begin{array}{l}\text { Retomando o funcionamento hidráulico (tanque, casa, cidade) } \\
\text {. Distribuição da água (prioridades socioeconômicas e políticas) }\end{array}$ \\
\hline & AC & $\begin{array}{l}\text { Ciclo da água no planeta e a interferência humana } \\
\text { Retomando e questionando todas as sete falas iniciais } \\
\text {. Propostas para a superação da falta d'água no bairro }\end{array}$ \\
\hline
\end{tabular}

Momentos pedagógicos: $E R^{*}$ - estudo da realidade; $O C$ *: organização do conhecimento: $A C$ *: aplicação do conhecimento

Fonte: Silva (2004, p. 405).

Os autores também enfatizam que o papel do professor durante a problematização inicial é diagnosticar apenas o que os estudantes sabem e pensam sobre uma determinada situação. É ele que organiza a discussão, não para fornecer explicações prontas, mas, sim, para buscar o questionamento das interpretações assumidas pelos estudantes. A dinâmica recomendada para essa etapa segue, num primeiro momento, a discussão em pequenos grupos, para depois ser compartilhada no grande grupo (DELIZOICOV, 2001).

É importante lembrar que, na forma como que foi concebida a problematização inicial nos momentos pedagógicos, também, se fazem presentes os conceitos prevalentes, não importando se são espontâneos ou não. Isso quer dizer que os estudantes podem explicitar sua concepção científica acerca das questões desafiadoras que lhes são apresentadas. Todavia, a problematização inicial é mais ampla, não envolve apenas os conceitos científicos e espontâneos, pois o pano de fundo é um problema que está orientando a problematização. Isto é, as perguntas realizadas no primeiro momento, que buscam trazer à tona as concepções dos estudantes acerca de determinada situação, são decorrentes de um problema que fundamenta todo o processo didático-pedagógico. Em suma, os questionamentos realizados na problematização inicial emergem de um problema, de uma contradição.

Ainda que essa característica da problematização inicial seja compartilhada tanto por Silva (2004) como por Delizoicov (1991, 2008), por Delizoicov, Angotti e Pernambuco (2002) 
e Pernambuco (1994), o fato de Delizoicov e Angotti (1991) não terem explicitado esse aspecto num livro que estrutura a abordagem de conceitos da Física, por exemplo, a partir de um tema - produção, distribuição e consumo de energia elétrica -, pode propiciar um entendimento ambíguo dos momentos pedagógicos do ponto de vista de fundamentação e do tratamento sistemático, o que pode dar uma dimensão exclusivamente metodológica a essa dinâmica.

$\mathrm{Na}$ Situação de Estudo, a primeira etapa da dinâmica de sala de aula também é denominada problematização, que, segundo Auth (2002), busca explicitar o primeiro entendimento que os alunos têm sobre uma determinada problemática, em que fica posta a necessidade de novos conhecimentos. É nesse momento em que os estudantes também são desafiados acerca de entendimentos sobre algum aspecto relacionado ao tema que faça parte de sua vivência. Nessa etapa, o professor traz para a discussão algumas palavras que mostram outras possibilidades de se compreender a situação problemática. Essas palavras, sempre conceitos sob o ponto de vista vygotskyano, começam a produzir algum sentido novo e podem vir a se tornar conceitos no decorrer do estudo. Elas orientam a discussão, embora os estudantes tenham total autonomia para usar suas palavras na produção dos entendimentos próprios. Cria-se, assim, a necessidade do estudo para se compreender a situação.

Nessa etapa, problematiza-se o conceito espontâneo do estudante mediante a introdução do conceito científico, para se abordar um problema que está vinculado a uma situação real do contexto do estudante, como o efeito estufa, a camada de ozônio e a chuva ácida. Ao se questionarem aspectos relacionados a essas situações, denominadas de problema no âmbito da Situação de Estudo, o professor vai fazer referência a uma palavra que, no decorrer das demais etapas, vai se tornar um conceito para o estudante. Isso não significa que o questionamento realizado na problematização tenha como referência os conceitos científicos, pois é preciso proporcionar uma interação dialógica que será possível se os estudantes se sentirem desafiados por meio das questões relacionadas às situações que lhes são familiares.

Em suma, a problematização na Situação de Estudo tem a função de significar as linguagens que vão se tornar uma discussão conceitual. Então, o professor precisa saber os conceitos científicos centrais sobre os quais necessita trabalhar e introduzir a palavra necessária. Um exemplo disso é apresentado por Maldaner (2007b) na Situação de Estudo "Ar Atmosférico", a qual está estruturada a partir da disciplina de Química. A atmosfera é uma situação da vivência e permite a significação de muitos conceitos iniciais de química. Os estudantes têm muito a dizer sobre ela e conhecem os problemas que estão ligados à atmosfera, como: a presença do ozônio na alta e na baixa atmosfera, a chuva-ácida em centros urbanos, o efeito estufa na regulação da temperatura da superfície da Terra, entre outras. Esses problemas, no entanto, só serão compreendidos se alguns conceitos básicos de Química, Física e Biologia forem significados nesse contexto, adquirindo sentido. As perguntas que caracterizam a problematização são, por exemplo: "De que é feita ou constituída uma porção de ar atmosférico?"; "Como se constituiu e se mantém a atmosfera terrestre?"; "Como podemos modificar a composição de uma amostra original de ar atmosférico?".

Maldaner (2007b) explica que:

Ao fazer essas perguntas em sala de aula sobre a composição do ar, costumam aparecer respostas como: gases, poeira, fumaça, poluentes, etc. Essas não são, ainda, respostas que interessam sob o ponto de 
vista da Química. Uma nova pergunta, por exemplo, [quais gases?], permite encaminhar respostas mais interessantes sob o ponto de vista de significação dos primeiros conceitos químicos, pois os estudantes começam a nomear substâncias que compõem a porção gasosa do ar atmosférico: oxigênio, nitrogênio, gás carbônico, vapor de água e outras. (MALDANER, 2007b, p. 21 - grifos do autor)

Como o aluno precisa formar um pensamento sobre uma determinada situação real, a exemplo do "Ar atmosférico", a introdução da palavra é necessária para permitir o pensamento sistematizado. É importante que a palavra representativa do conceito esteja presente, que seja utilizada na interação, que docentes e estudantes se detenham nela, discutam sentidos e significados que deverão ter em um contexto específico de uma disciplina ou no contexto interdisciplinar (MALDANER et al., 2001). Vale lembrar que a palavra em Vygotsky (2001), no inicio, é apenas um som, mas já apresenta algum sentido para o estudante em um determinado contexto, isso porque o sentido sempre é contextual e subjetivo. Desta forma, já existe a intencionalidade de introduzir uma palavra, e em torno dela vai se desenvolver o conceito, consequentemente, o entendimento da situação problemática.

Em vista do exposto, o processo da significação conceitual tem início na problematização - primeira etapa da Situação de Estudo -, o que faz com que sua configuração seja conceitual. Isto é, seu objetivo é trazer à tona um problema que está presente na vivência dos estudantes, em que o seu equacionamento necessita de novas palavras representativas de conceitos, sendo este o primeiro passo da significação conceitual.

$\mathrm{Na}$ primeira etapa do desenvolvimento de um tema em sala de aula, tendo como referência tanto os momentos pedagógicos quanto a Situação de Estudo, é possível identificar que, em ambos, os estudantes são desafiados a expor seus entendimentos acerca de situações vinculadas ao tema em questão. Além das semelhanças entre as propostas curriculares, na primeira etapa do desenvolvimento em sala de aula, também há um aspecto que revela a especificidade da abordagem temática freireana e da Situação de Estudo, o qual diz respeito à configuração de um problema - objeto de estudo. Na abordagem temática freireana, a escolha do problema que passa a organizar todo o processo didático-pedagógico segue a investigação temática, em que a problematização consiste em abordar determinados problemas que são manifestações de contradições locais (FREIRE, 1987), a exemplo da falta de água no município de Americanópolis/SP (SILVA, 2004) e da questão da agricultura na Guiné-Bissau (DELIZOICOV; CASTILHO, 1980). Em função disso, a atuação docente, nesse momento da problematização inicial, não é a de introduzir a palavra que está relacionada a um determinado conceito científico, o que, no caso da Situação de Estudo, é essencial. A meta da problematizaçãa inicial na abordagem temática freireana é a de preparar a introdução do conceito científico no momento seguinte, isto é, na organização do conhecimento. Deseja-se conscientizar o aluno da necessidade de outros conhecimentos para a compreensão do problema, isto é, os conceitos científicos já selecionados para serem abordados na organização do conhecimento (DELIZOICOV, 1991, 2008; DELIZOICOV; ANGOTTI; PERNAMBUCO, 2002).

$\mathrm{Na}$ Situação de Estudo, o problema a ser explorado está relacionado com os conceitos estruturados e estruturadores de uma nova compreensão a serem desenvolvidos em sala de aula, e aí está a importância dos conceitos espontâneos dos estudantes, pois mediante o conhe- 
cimento de maior generalidade, o científico, é possível tomar consciência dos conhecimentos espontâneos e da sua insuficiência. Os conhecimentos espontâneos e científicos se interinfluenciam, de acordo com Vygotsky (2001), em movimentos opostos, em que os primeiros caminham para a abstração e os segundos para a compreensão da situação concreta. Por exemplo, na Situação de Estudo "Ar Atmosférico", o efeito estufa é um conceito que as pessoas, no diaa-dia, têm ligado, muitas vezes, apenas à compreensão de malefício, mas a introdução de conceitos da Ciência permite que o sujeito passe a compreender o efeito estufa na regulação da temperatura da superfície da Terra. Em síntese, o objeto de estudo na Situação de Estudo é um problema de dimensão conceitual, o que, portanto, difere da abordagem temática freireana, na qual o problema tem relação com as contradições locais em que vivem os estudantes.

\section{Organização do conhecimento e primeira elaboração}

A segunda etapa dos momentos pedagógicos, denominada organização do conhecimento, compreende, no entender de Delizoicov $(1991,2008)$ e de Delizoicov, Angotti e Pernambuco (2002), o estudo sistemático dos conhecimentos envolvidos no tema e na problematização inicial. Isto é, são estudados os conhecimentos científicos necessários para a melhor compreensão dos temas e das situações significativas. Nesse momento da atividade pedagógica é importante enfatizar que os conhecimentos científicos são ponto de chegada:

A abordagem dos conceitos científicos é ponto de chegada, quer da estruturação do conteúdo programático quer da aprendizagem dos alunos, ficando o ponto de partida com os temas e as situações significativas que originam, de um lado, a seleção e organização do rol de conteúdos, ao serem articulados com a estrutura do conhecimento científico, e, de outro, o início do processo dialógico e problematizador. (DELIZOICOV; ANGOTTI; PERNAMBUCO, 2002, p. 194)

Os conhecimentos científicos como ponto de chegada no processo de ensino-aprendizagem contribuem para o entendimento dos Temas Geradores (DELIZOICOV, 1991, 2008; SILVA, 2004; DELIZOICOV; ANGOTTI; PERNAMBUCO, 2002; PERNAMBUCO, 1994; PONTUSCHKA, 1993). Para que ocorra a apreensão desse conhecimento científico, por parte do estudante, Delizoicov (1991) afirma que a prática educativa necessita ser desenvolvida segundo um modelo didático-pedagógico que propicia a ruptura entre o conhecimento do estudante e o conhecimento sistematizado, isto é, entre a "cultura primeira" e "cultura elaborada" (SNYDERS, 1988). É nessa ocasião que Delizoicov (1991) explora a relação entre o processo-produto do conhecimento do aluno e o do conhecimento científico, conforme representação da Figura 1.

Para Delizoicov (1991), o processo de produção de conhecimento tanto do aluno quanto da Ciência não pode ser desconsiderado pelo professor durante o planejamento, a organização e o desenvolvimento da atividade pedagógica de apropriação do produto do conhecimento científico pelo educando. Em outros termos, para o autor, o professor necessita aprender não somente o "produto" construído pelo educando - no caso, a informação da

Ciência \&̊ Educação, v. 18, n. 1, p. 1-22, 2012 
Figura 1. Relação entre o processo-produto do conhecimento do aluno e o do conhecimento científico.

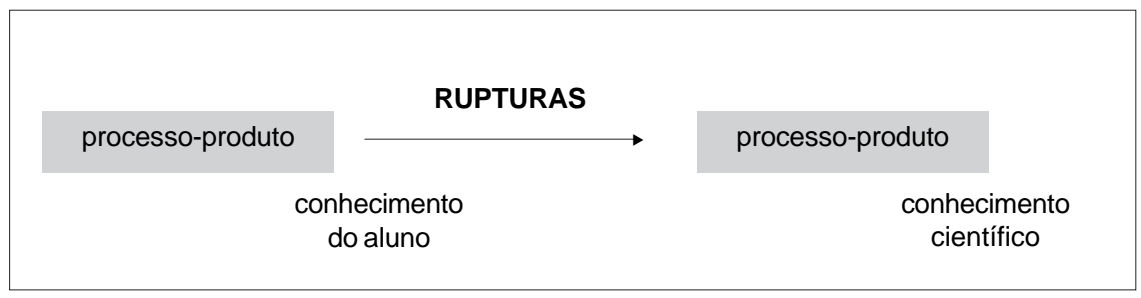

Fonte: Delizoicov; Angotti; Pernambuco (2002, p. 196).

concepção alternativa -, mas, também, o seu "processo" de construção, isto é, como essa informação se articula com os valores e "filosofias" da comunidade na qual é construída.

Ao caracterizar a ruptura, Delizoicov (1991) destaca como imprescindível considerar a continuidade no processo de interpretação de fenômenos. Defende a ocorrência de continuidade, a qual é garantida através da ruptura, em que a apreensão do objeto do conhecimento pelo educando ocorrerá por hipótese segundo um processo de continuidade-ruptura-continuidade. Para o autor:

[...] o conhecimento prevalente do educando - particularmente o caracterizado pelas concepções alternativas - implica na continuidade do conbecimento vulgar para interpretação dos fenômenos. A aquisição dos paradigmas da Ciência deverá ocorrer num processo de ruptura com aquele conhecimento prevalente para que seja possível a continuidade da interpretação dos fenômenos, via conhecimento produzido pela Ciência e não pelo conhecimento vulgar. (DELIZOICOV, 1991, p. 62 grifos do autor)

É importante destacar que a noção de ruptura foi estabelecida por Delizoicov (1991) a partir dos pressupostos de Kuhn (1975), apresentando sintonia com o que ocorre na passagem de um paradigma para outro, durante as "revoluções científicas". Isto é, durante a mudança de paradigma, dependendo do problema particular a ser investigado, o pesquisador não abandona totalmente os paradigmas, pois devido à sua formação poderá transitar e compartilhar tanto do paradigma "velho" como do "novo". Por exemplo, dependendo do problema a ser investigado, os paradigmas podem ser os da Física Clássica ou os da Física Quântica.

É nesse sentido que, para Delizoicov (1991), a ocorrência de ruptura entre o conhecimento prevalente do educando e os paradigmas científicos não significa abandono, mas sim a possibilidade de conviver com diferentes explicações para os fenômenos que constituem a vivência do educando. O estudante, ao se apropriar do conhecimento produzido pela Ciência, tem a possibilidade de transitar entre esse conhecimento e o seu conhecimento prevalente, particularmente caracterizado pelas concepções alternativas. Essa convivência entre um conhecimento e outro pode ser exemplificada por meio do perfil conceitual, estabelecido por Mortimer $(1996,2000)$ a partir das ideias de Bachelard (1996), em que o indivíduo pode transitar entre as diversas zonas de perfis, desde que ele tenha consciência delas. 
Ressalta-se que a seleção dos conhecimentos científicos a serem abordados na organização do conhecimento é realizada antes de serem desenvolvidos em sala de aula, durante a redução temática (DELIZOICOV, 1982, 1991, 2008; SILVA, 2004; PERNAMBUCO, 1994; FREIRE, 1987). Isto é, o educador, nesse momento, tem um planejamento prévio dos conceitos científicos a serem trabalhados com os alunos. Por exemplo, Silva (2004) - no Quadro 1 apresenta o planejamento prévio das atividades a serem desenvolvidas na $6^{a}$ série do Ensino Fundamental, em que na organização do conhecimento, no tópico "IV Estação de tratamento de água", são explorados conhecimentos relacionados às propriedades físico-químicas da água, como a solubilidade, miscibilidade, densidade, etc., além de fracionamento de misturas e a utilização da água pelos seres vivos.

Outro exemplo da organização do conteúdo programático da disciplina de Ciências Naturais, por meio do processo da investigação temática, é apresentado por Delizoicov e Castilho (1980) no material elaborado para a $5^{a}$ série, durante o projeto desenvolvido na Guiné-Bissau. Por exemplo, no tópico "Instrumentos Agrícolas" a organização do conbecimento, aqui denominada de estudo científico, explora conhecimentos científicos relacionados às transformações de energia química em mecânica (máquina simples), transformações de energia química em energia mecânica e/ou elétrica (motores a combustão), e transformação de energia mecânica em energia elétrica (hidrelétrica).

Para que os alunos compreendam cientificamente as situações problematizadas, o papel do professor na organização do conhecimento consiste em desenvolver diversas atividades. Dentre elas, está a utilização de textos de divulgação científica seguindo a dinâmica dos momentos pedagógicos, como sugere Alvetti e Delizoicov (1998). Além disso, outras atividades também podem permear esse processo, como aquelas relacionadas à produção escrita envolvendo a narrativa (RIBEIRO; MARTINS, 2007), utilização das tecnologias da informação e comunicação (GIORDAN, 2006) e a dinâmica discursiva (MORTIMER; SCOTT, 2002).

$\mathrm{Na}$ Situação de Estudo, a segunda etapa é caracterizada, por Auth (2002), de primeira elaboração, o que remete para atividades que envolvem, especialmente, textos de aprofundamento sobre as circunstâncias que foram apresentadas na primeira etapa - problematização. É por meio dessas atividades que os estudantes vão ter o primeiro contato com conhecimentos científicos para além da palavra representativa de um determinado conceito. Esse primeiro contato com a palavra representativa de um conceito, num determinado contexto, é realizado mediante a orientação do professor em diversas atividades. Por exemplo, na Situação de Estudo "Ar Atmosférico", essa etapa consiste na orientação dos estudantes, em grupo, a desenvolverem pesquisas bibliográficas e eletrônicas complementares:

[...] sobre as características das substâncias participantes do ar atmosférico, o uso comercial de alguma delas, o ciclo de conservação delas na atmosfera; - sobre a composição da atmosfera terrestre há muitos anos atrás e sua modificação com o tempo (tempo geológico); - sobre a relação entre composição do ar atmosférico e a atividade biológica geral, envolvendo, também, a atividade tecnológica (humana). (MALDANER, 2007b, p. 24) 
Essas atividades permitem, ao estudante, localizar situações em que as palavras representativas relativas ao conceito de substância, por exemplo, são utilizadas no contexto de situações que podem fazer parte do meio em que vive. Nessa ocasião, o estudante entra em contato com situações em que estão presentes elementos científicos introduzidos por meio da palavra; isso não significa que ele já tenha o entendimento necessário. Neste momento serão agregados os significados desejáveis e necessários à palavra que representa o conceito sistematizado, que foi introduzida na problematização - primeira etapa da Situação de Estudo.

Por exemplo, na Situação de Estudo "Ar Atmosférico", é na primeira elaboração que são apresentadas as fórmulas representativas das substâncias que compõem o material denominado de ar atmosférico, bem como características próprias dessas substâncias, algumas de conhecimento dos estudantes e outras não. Também são produzidos significados de conceitos diretamente vinculados à linguagem química, como as fórmulas representativas das substâncias. Por exemplo, a substância água, ao ser representada por uma fórmula química " $\mathrm{H}_{2} \mathrm{O}$ " chama-se atenção para o significado das letras e números, em que $\mathrm{H}$ com índice 2 representa dois átomos do elemento químico hidrogênio, e $\mathrm{O}$ sem índice representa um átomo do elemento químico oxigênio. Destaca-se que cada elemento é expresso por um símbolo, letra maiúscula, a qual, em alguns casos, é seguida de uma minúscula. Além disso, o índice é usado na representação para expressar a relação existente entre os átomos da fórmula química.

A partir disso, o estudante terá condições de elencar os elementos constituintes das substâncias componentes do ar atmosférico e o número de vezes em que cada elemento químico participa na formação da menor partícula da referida substância, no caso, a sua molécula (MALDANER, 2007b). Esse passo na significação conceitual, o de situar um determinado conceito no contexto da vivência do sujeito mediante o uso induzido da palavra que o representa desde o início, permite que se comecem a construir os primeiros sentidos do conceito. Este, ao ser retomado em outros contextos, evolui em seu significado e atinge novos níveis de abstração. Dessa forma, a primeira elaboração no contexto da Situação de Estudo é o primeiro contato do estudante com situações em que estão sendo usadas não apenas palavras representativas de um determinado conceito, mas também lhe são agregados outros significados, como, por exemplo, propriedades químicas e linguagem química mais evidente, que são fórmulas químicas que aparecem constantemente no cotidiano dos alunos. Esses novos significados possibilitam, por parte do estudante, um entendimento mais complexo de determinados materiais, a exemplo do ar ou substâncias como água, oxigênio e outras que compõem o ar atmosférico. Em suma, ao ter como referência materiais e substâncias conhecidas de seu cotidiano, características do ponto de vista da Química adquirem sentidos e o estudante pode melhor compreender aspectos básicos do conhecimento químico sobre o mundo.

A partir da caracterização da primeira elaboração presente na Situação de Estudo e da organização do conhecimento na abordagem temática freireana, é possível sinalizar articulações vinculadas, em especial, à abordagem dos conhecimentos científicos, que, em ambos, é central. Contudo, a primeira elaboração caracteriza um segundo nível da abordagem dos conceitos, em que os estudantes se deparam com situações que apresentam conceitos científicos num nível mais elevado que na primeira elaboração. Exploram-se os conceitos científicos, mas sem o devido aprofundamento, aspecto que difere da organização do conhecimento - segunda etapa dos momentos pedagógicos. Nessa são realizadas diversas atividades com a finalidade de apreensão dos conceitos científicos, por parte dos estudantes, de forma que eles tenham condições de 
compreender as situações iniciais, propostas na problematização inicial, e também outras apresentadas na aplicação do conbecimento. Na Situação de Estudo buscam-se novos contextos, já mais distantes do contexto inicial em que o conceito foi introduzido pela primeira vez. Com isso os significados iniciais podem evoluir.

Em suma, a primeira elaboração extrapola o contexto inicial, pois o objetivo está mais direcionado à significação conceitual do que, propriamente, ao entendimento do contexto de partida. Assim, em ambos os casos, primeira elaboração (Situação de Estudo) e organização do conhecimento (momentos pedagógicos), a recontextualização e a significação do conhecimento científico são o produto da ação pedagógica. A partir dele, novos contextos e o contexto inicial podem ser analisados e compreendidos em nível mais elevado e com tomada de consciência. Isso está de acordo com Vygotsky (2002), que defende que um conhecimento de maior generalidade permite a tomada de consciência de situações anteriores, como as situações do cotidiano ou escolarização anterior. É nesse sentido que a primeira elaboração configura-se como um dos procedimentos a serem realizados na organização do conhecimento, isto é, a primeira elaboração pode se constituir na primeira etapa da organização do conhecimento, uma vez que ambas abordam o conhecimento científico, embora em diferentes níveis.

\section{Aplicação do conhecimento e função da elaboração e compreensão conceitual}

A terceira etapa dos momentos pedagógicos é denominada de aplicaşão do conhecimento, que, segundo Delizoicov (1991, 2008) e Delizoicov, Angotti e Pernambuco (2002), destina-se a empregar o conhecimento do qual o estudante vem se apropriando para analisar e interpretar as situações propostas na problematização inicial e outras que possam ser explicadas e compreendidas pelo mesmo corpo de conhecimentos.

$\mathrm{Na}$ visão dos autores, nessa etapa, o papel do professor consiste em desenvolver diversas atividades para capacitar os alunos a utilizarem os conhecimentos científicos explorados na organização do conbecimento, com a perspectiva de formá-los para articular constantemente a conceituação científica com situações que fazem parte de sua vivência. Destaca-se, nesse momento, a busca pela "generalização da conceituação", isto é, a identificação e o emprego da conceituação científica envolvida, em que "é o potencial explicativo e conscientizador das teorias científicas que deve ser explorado" (DELIZOICOV; ANGOTTI; PERNAMBUCO, 2002 , p. 202). A partir disso, o estudante tem a potencialidade de compreender cientificamente as situações abordadas na problematização inicial, motivo pelo qual, nesse terceiro momento, volta-se às situações iniciais, que agora passam a ser entendidas a partir do olhar da Ciência.

Além disso, na aplicação do conbecimento, são exploradas situações diferenciadas daquelas apresentadas no primeiro momento. Por exemplo, no estudo de Silva (2004), a abordagem de outros aspectos compreende a interpretação de situações que vão além daquelas que envolvem o dia-a-dia do estudante, como a compreensão do "Ciclo da água no Planeta e a interferência humana", apresentada no Quadro 2 no momento da aplicação do conbecimento.

A aplicação do conhecimento culmina com a defesa de Freire $(2005$, p. 87) de que "o fundamental é deixar claro ou ir deixando claro aos educandos esta coisa óbvia: o regional emerge do local tal qual o nacional surge do regional e o continental do nacional como o 
Momentos pedagógicos e as etapas ...

Quadro 2. Organização do conteúdo programático seguindo os momentos pedagógicos

\begin{tabular}{|l|l|l|}
\hline $\begin{array}{l}\text { VII Distribuição } \\
\text { social da água - } \\
\text { visão geral do } \\
\text { processo e } \\
\text { extrapolações } \\
\text { para o planeta }\end{array}$ & Fala 7: & Mesmo nos períodos chuvosos há falta de água; \\
\cline { 2 - 4 } & OC & $\begin{array}{l}\text { O que há de comum entre o funcionamento de um equipamento hidráulico e a } \\
\text { distribuição da água urbana? Quais são os fatores reguladores nos dois níveis? } \\
\text { Só a falta de chuva explica o abastecimento precário em alguns bairros? }\end{array}$ \\
\cline { 2 - 3 } & AC & $\begin{array}{l}\text {. Retomando o funcionamento hidráulico (tanque, casa e cidade) } \\
\text {-Distribuição da água (prioridades socioeconômicas e políticas) }\end{array}$ \\
\hline $\begin{array}{l}\text { - Ciclo da água no planeta e a interferência humana } \\
\text {-Retomando e questionando todas as sete falas iniciais } \\
\text {.Propostas para a superação da falta d'água no bairro }\end{array}$ \\
\hline
\end{tabular}

Fonte: Silva $(2004$, p. 405).

mundial emerge do continental". Assim as situações abordadas na problematização inicial, que, no exemplo de Silva (2004), corresponde basicamente à falta de água na residência e no bairro em que vive o estudante, são referências para a análise de problemas regionais, nacionais e mundiais, não se restringindo à realidade local do aluno.

$\mathrm{Na}$ Situação de Estudo, a terceira etapa é caracterizada como função da elaboração $e$ compreensão conceitual, momento relacionado ao nível conceitual atribuído a cada ciclo de estudos ou série, e a volta ao problema em foco, quando deve ocorrer a sistematização (AUTH, 2002). Nesse momento, são exploradas com os estudantes, situações que apresentam explicações de cunho científico, na maioria das vezes trabalhadas no âmbito de textos científicos. Nesses textos, o aluno começa a identificar as palavras representativas dos conceitos, com as quais já teve contato nas etapas anteriores, suas fórmulas e sua significação no contexto em que é empregada. Por exemplo, em um dos textos discutidos na Situação de Estudo "Ar Atmosférico" (MALDANER, 2007b), cada vez que uma substância química é mencionada como oxigênio, água, hidrogênio e outras - o estudante terá condições de identificar a sua representação química, bem como o significado da simbologia presente, pois essa já lhe foi apresentada em etapa anterior.

De posse da palavra e de suas representações químicas iniciais (fórmula química), a terceira etapa da Situação de Estudo configura o momento em que são proporcionadas novas significações, como equações e transformações químicas. Com isso, o estudante poderá compreender o que ocorre, por exemplo, com o ozônio na atmosfera. O texto presente no Anexo 1 ilustra essa etapa, em que há necessidade de o estudante ter a compreensão dos significados químicos das representações, como, por exemplo, do oxigênio e do ozônio, para que seja possível visualizar e entender aspectos de transformação e de conservação. No caso, o elemento oxigênio é conservado e substâncias deixam de existir e novas são produzidas. O fragmento do texto "Ciclo do ozônio e vida no Planeta Terra" (Anexo 1), dá uma ideia disso.

Ao compreender o ciclo do ozônio e sua relação com o Planeta Terra, é possível inferir que o estudante começa a dominar uma nova linguagem, em que terá uma compreensão conceitual acerca das transformações químicas, denominada de apropriação de um pensamento químico. Isto é, o estudante terá o conceito verdadeiro, ao qual Vygotsky (2001) se refere, 
obtido por meio do processo de formação de conceitos que envolve o movimento ascendente e descendente entre os conceitos científico e cotidiano. Esses movimentos, de acordo com Vygotsky (2001, 2005), possuem processos construtivos opostos: os espontâneos partem do concreto para o abstrato, e os científicos, do abstrato para o concreto. Neste caso, há uma interação dialética entre os conhecimentos, desempenhando diferentes funções na teoria do desenvolvimento e resultando no que Vygotsky (2001) denomina de "conceitos verdadeiros".

Esses conceitos são compreensões mais aprofundadas do sujeito sobre um domínio específico que, no entender de Schroeder (2008), possibilita libertá-lo de seu contexto perceptual imediato, o que pode indicar uma relação com o novo nível de entendimento, um nível de desenvolvimento potencial. Aspecto que parece culminar com a questão da ruptura ${ }^{5}$ discutida por Delizoicov (1991), que não significa abandono das concepções espontâneas dos estudantes, mas sim, uma nova interpretação, uma consciência máxima possivel, no sentido de Goldmann (1974), conforme destacado nas análises de Freire (1987) e de Delizoicov (1991, 2008), que possibilita a emersão do sujeito de seu contexto imediato e a transição entre os conceitos espontâneos e científicos.

É nessa terceira etapa da Situação de Estudo que se busca a generalização do conceito, porque seu propósito maior é a significação conceitual. Aqui é importante lembrar que a generalização, na perspectiva vygotskyana, está presente desde a primeira etapa, desde a Problematização, isso porque a palavra representa um ato de generalização, como afirma Vygotsky (2001):

A essência do seu desenvolvimento é, em primeiro lugar, a transição de uma estrutura de generalização a outra. Em qualquer idade, um conceito expresso por uma palavra representa uma generalização. Mas os significados das palavras evoluem. Quando uma palavra nova, ligada a um determinado significado, é apreendida pela criança, o seu desenvolvimento está apenas começando; no início ele é uma generalização do tipo mais elementar que, à medida que a criança se desenvolve, é substituída por generalizações de um tipo cada vez mais elevado, culminando na formação dos verdadeiros conceitos. (VYGOTSKY, 2001, p. 246)

Outro aspecto a destacar na função da elaboração e compreensão conceitual é a retomada das questões iniciais apresentadas na problematização, pois há a finalidade de se obter uma compreensão conceitual dessas. Além disso, destaca-se que, a partir da formação de um pensamento conceitual, o estudante terá condições de compreender outras situações, para além daquelas que lhe foram apresentadas durante o desenvolvimento da Situação de Estudo. Com base nisso, na terceira etapa, também são apresentadas outras situações sobre as quais os estudantes têm algo a dizer, e que, na maioria das vezes, representam uma problemática mais ampla, uma dimensão mais global. Na Situação de Estudo "Ar Atmosférico", por exemplo, essas situações estão relacionadas ao efeito estufa e à chuva ácida.

${ }^{5}$ É necessário aprofundar a relação entre o conceito verdadeiro em Vygotsky e a ruptura à qual se refere Delizoicov (1991). 
Em vista do exposto, é possível constatar relações entre a função de elaboração e compreensão conceitual no contexto da Situação de Estudo e a aplicação do conhecimento na abordagem temática freireana. Uma delas é a retomada das questões iniciais que ocorre em ambas as propostas. Contudo, na abordagem temática freireana, volta-se às situações significativas que representam as contradições locais dos estudantes, em que há necessidade de "readmirar" o problema. Na Situação de Estudo volta-se, também, para as situações iniciais, porém estão mais próximas de um problema de dimensão conceitual e temas mais amplos e gerais.

Outro aspecto que também pode apresentar relações entre a função de elaboraşão e compreensão conceitual e a aplicação do conhecimento diz respeito à generalização da conceituação, que em ambas é central. Contudo, na Situação de Estudo, a generalização já começa na primeira etapa, na problematização, isso porque a palavra, que representa um conceito na perspectiva vygotskyana, pode apresentar generalizações do tipo mais elementares, sendo, na última etapa - função de elaboração e compreensão conceitual - substituída por generalizações mais elevadas, culminando com a formação dos verdadeiros conceitos (VYGOTSKY, 2001).

É importante destacar que, na terceira etapa - função de elaboração e compreensão conceitual -, há uma abordagem mais sistemática dos conhecimentos estruturados, o que permite inferir uma semelhança mais próxima da organização do conhecimento, do que da aplicação do conhecimento. Assim, há uma sintonia entre o segundo momento pedagógico e a terceira etapa da Situação de Estudo, uma vez que, em ambos os casos, ocorre uma discussão mais sistemática em torno da relação entre os conceitos científicos e cotidianos. Isto é, na organização do conbecimento, a argumentação de Delizoicov (1991) acerca da ruptura entre o conhecimento do aluno e o conhecimento científico está muito próxima do conceito verdadeiro - resultado do movimento entre os conhecimentos científico e cotidiano em Vygotsky (2001) - que caracteriza a função de elaboração e compreensão conceitual na Situação de Estudo. Tal relação é possível, porque, em ambas, o foco é a apreensão dos conhecimentos historicamente construídos, por parte dos estudantes.

\section{Algumas considerações finais e contribuições para o ensino de Ciências}

É importante destacar que, na abordagem temática freireana, os momentos pedagógicos (DELIZOICOV, 1991, 2008; DELIZOICOV; ANGOTTI; PERNAMBUCO, 2002) estão relacionados à perspectiva pedagógica e a ênfase na dimensão cognitiva está presente no que se refere aos níveis de consciência real efetiva e consciência máxima possivel, tendo como base Goldmann (1974). Em outros termos, a estruturação com o uso dos momentos pedagógicos se configura em uma dinâmica de organização do trabalho para efetivar esse esforço da abordagem temática freireana com a dimensão cognitiva, e, portanto, na etapa de sala de aula - quinta etapa da investigação temática - assume o papel de pedagogicamente criar condições para que os educandos transitem da consciência real efetiva para a consciência máxima possivel. No entanto, essa dimensão cognitiva pode ser potencializada na abordagem temática freireana por meio de alguns elementos presentes na Situação de Estudo, com o aporte das ideias de Vygotsky.

Embora haja aspectos semelhantes entre as propostas, elas apresentam certas especificidades. Por exemplo, a abordagem temática freireana se diferencia da Situação de Estudo no sentido de apresentar critérios mais explícitos para a escolha de problemas. Esses critérios estão relacionados com o processo de humanização presente na obra de Vygotsky, conforme 
discutido por Gehlen (2009). Desta forma, a abordagem temática freireana, como concepção de estrutura curricular, não depende apenas da dimensão conceitual, ou seja, ela é uma articulação de problemas - contradições sociais e existenciais - com os conceitos científicos. O fato de existir uma sintonia entre as propostas no que concerne à dimensão cognitiva, faz com que a Situação de Estudo apresente elementos que contribuem no aprofundamento da abordagem temática freireana, aspecto sintetizado na Figura 2.

Figura 2. Complementaridade entre os momentos pedagógicos e as etapas da situação de estudo

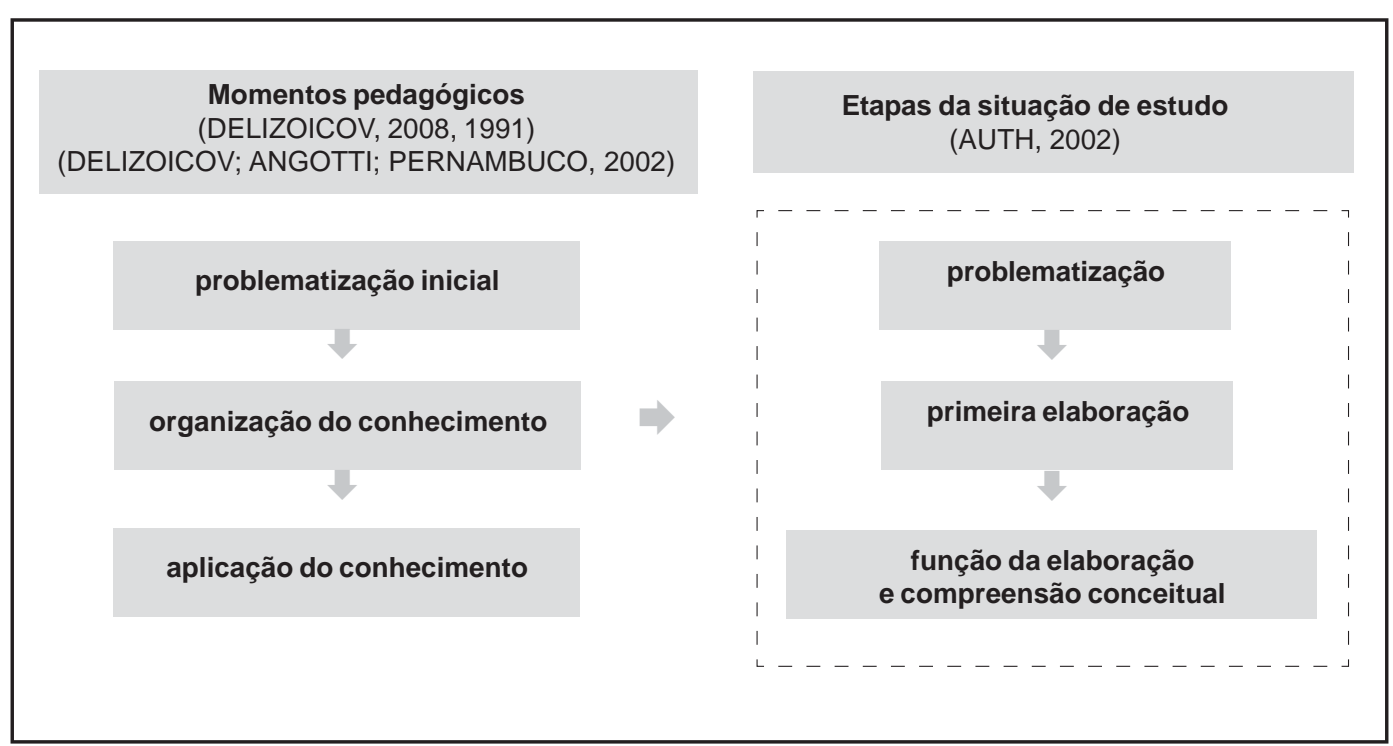

Fonte: Gehlen (2009, p. 199).

A Figura 2 sintetiza a interrelação entre os momentos pedagógicos e a Situação de Estudo, em que as etapas desta última contribuem para melhor sistematizar a abordagem dos conhecimentos científicos na organização do conhecimento da abordagem temática freireana. A Situação de Estudo, ao centralizar suas discussões no processo da significação conceitual, estabelece etapas a serem desenvolvidas em sala de aula com esse propósito, ou seja, fundamenta cada etapa para a formação do pensamento conceitual do estudante. Com isso, há uma especificidade em se planejar o processo da apropriação da dimensão científica, aspecto que também está presente nos momentos pedagógicos. Contudo, uma articulação entre as etapas da Situação de Estudo com a organização do conhecimento da abordagem temática freireana pode possibilitar uma abordagem para sala de aula fundamentada por uma concepção de desenvolvimento cognitivo.

As etapas da Situação de Estudo - problematização, primeira elaboração, função da elaboração e compreensão conceitual -, que configuram o processo da significação conceitual, contribuem no contexto dos momentos pedagógicos, uma vez que a organizaçãa do conhecimento pode ser poten- 
Momentos pedagógicos e as etapas ...

cializada seguindo as etapas da significação conceitual abordadas pela Situação de Estudo. Agregam-se, portanto, à organização do conhecimento, elementos da perspectiva vygotskyana.

Por outro lado, há uma importante contribuição dos momentos pedagógicos para a questão da significação conceitual na Situação de Estudo, como a problematização inicial e a aplicação do conhecimento. Os momentos pedagógicos podem contribuir na estruturação da dinâmica de sala de aula na Situação de Estudo, em que o ponto de partida da proposta tenha como referência problemas com características semelhantes às da abordagem temática freireana, isto é, emergem de situações da vivência dos estudantes e que apresentam contradições locais (FREIRE, 1987).

Ao trazer para a Situação de Estudo a problematização inicial, com base na perspectiva freireana, é importante destacar que essa relação é possível porque Vygotsky (2001) propõe a significação conceitual em situação de enfrentamento de um problema ou situação problemática. Ou, ainda, diante de uma necessidade, que pode ser uma necessidade do contexto sociocultural no qual o estudante está inserido e ao qual precisa dar conta através de bom aproveitamento escolar.

Além das aproximações entre Freire e Vygotsky presentes na literatura, no campo teórico (GEHLEN; MALDANER; DELIZOICOV, 2010), outras articulações mostraram-se possíveis no campo pedagógico, como é o caso da complementaridade entre as etapas de planejamento e desenvolvimento em sala de aula da abordagem temática freireana e da Situação de Estudo. Contudo, é preciso investigar essas articulações teóricas no contexto da Educação Básica, isto é, há necessidade de "uma maior aproximação dos problemas investigados pelo Ensino de Ciências com aqueles enfrentados pelo Ensino de Ciências" (DELIZOICOV, 2004, p. 145).

\section{Referências}

ALVETTI, M. A. S.; DELIZOICOV, D. Ensino de física moderna e contemporânea e a Revista Ciência Hoje. In: Encontro de Pesquisa em Ensino de Física, 6., 1998, Florianópolis. Resumos... Florianópolis: Sociedade Brasileira de Física, 1998.

ANDRADE, E. C. P.; CARVALHO, L. M. O Pró-Álcool e algumas relações CTS concebidas por alunos de $\sigma^{a}$ série do ensino fundamental. Ciência \& Educação, Bauru, v. 8, n. 2, p. 167-185, 2002.

ANGOTTI, J. A. P. Solução alternativa para a formação de professores de ciências: um projeto educacional desenvolvido na Guiné Bissau. 1982. 188 f. Dissertação (Mestrado em Educação) -Faculdade de Educação, Universidade de São Paulo, São Paulo, 1982.

AULER, D. et al. Transporte particular x coletivo: intervenção curricular pautada por interações entre ciência-tecnologia-sociedade. Enseñanza de las Ciencias, Barcelona, p. 1-5, 2005. Número extra.

AUTH, M. A. et al. Práticas pedagógicas na formação inicial em ciências: entre saberes e dissaberes. In: GALIAZZI, M. C. et al. (Org.). Aprender em rede na educação em ciências. Ijuí: Editora Unijuí, 2008. p. 177-194. 
AUTH, M. A. et al. Situação de Estudo na área de ciências do ensino médio: rompendo fronteiras disciplinares. In: MORAES, R.; MANCUSO, R. (Org.). Educação em ciências: produção de currículos e formação de professores. Ijuí: Editora Unijuí, 2004. p. 253-276.

AUTH, M. A. Formação de professores de ciências naturais na perspectiva temática e unificadora. 2002. 200 f. Tese (Doutorado em Educação) - Centro de Ciências da Educação, Universidade Federal de Santa Catarina, Florianópolis, 2002.

BACHELARD, G. A formação do espírito científico: contribuição para uma psicanálise do conhecimento. Rio de Janeiro: Contraponto, 1996.

BRASIL. Ministério da Educação. Secretaria de Educação Fundamental. Parâmetros curriculares nacionais: apresentação dos temas transversais. Brasília: MEC, 1997.

DELIZOICOV, D. Conhecimento, tensões e transições. 1991. 214 f. Tese (Doutorado em Educação) - Faculdade de Educação, Universidade de São Paulo, São Paulo, 1991.

Concepção problematizadora para o ensino de ciências na educação formal: relato e análise de uma prática educacional na Guiné-Bissau. 1982. 227 f. Dissertação (Mestrado em Ensino de Ciências) - Instituto de Física, Universidade de São Paulo, São Paulo, 1982.

La educación en ciencias y la perspectiva de Paulo Freire. Alexandria: revista de educação em ciência e tecnologia, Florianópolis, v. 1, n. 2, p. 37-62, 2008. Disponível em: $<$ http://www.ppgect.ufsc.br/alexandriarevista/numero_2/artigos/demetrio.pdf > . Acesso em: 10/03/2009.

Pesquisa em ensino de ciências como ciências humanas aplicadas. Caderno

Brasileiro de Ensino de Física, Florianópolis, v. 21, n. 2, p. 145-175, 2004.

Problemas e problematizações. In: PIETROCOLA, M. (Org.). Ensino de física: conteúdo, metodologia e epistemologia numa concepção integradora. Florianópolis: Ed. da UFSC, 2001. p. 125-150.

DELIZOICOV, D.; ANGOTTI, J. A. Física. São Paulo: Cortez, 1991.

DELIZOICOV, D.; ANGOTTI, J. A.; PERNAMBUCO, M. M. Ensino de ciências: fundamentos e métodos. São Paulo: Cortez, 2002.

DELIZOICOV, D.; CASTILHO, N. Ciências naturais: livro do aluno - 5a classe. Bissau: Imprensa Nacional da Guiné Bissau, 1980.

FREIRE. P. Pedagogia do oprimido. 17. ed. Rio de Janeiro: Paz e Terra, 1987.

Pedagogia da Esperança: um reencontro com a pedagogia do oprimido. 12 ed.

Rio de Janeiro: Paz e Terra, 2005.

GEHLEN, S. T. A função do problema no processo ensino-aprendizagem de ciências: contribuições de Freire e Vygotsky. 2009. 253 f. Tese (Doutorado em Educação Científica e Tecnológica) - Universidade Federal de Santa Catarina, Florianópolis, 2009. 
GEHLEN, S. T. et al. Freire e Vigotski no contexto da educação em ciências: aproximações e distanciamentos. Ensaio: pesquisa em educação em ciências, Belo Horizonte, v. 10, n. 2, p. 1-20, 2008.

GEHLEN, S. T.; MALDANER, O. A.; DELIZOICOV, D. Freire e Vygotsky: um diálogo com pesquisas e sua contribuição na educação em ciências. Pro-Posições, Campinas, v. 21, n. 1, p. 129-148, 2010.

GIORDAN, M. Algumas questões técnicas e metodológicas sobre o registro da ação na sala de aula: captação e armazenamento digitais. In: SANTOS, F. M. T.; GRECA, I. M. (Org.). A pesquisa em ensino de ciências no Brasil e suas metodologias. Ijuí: Editora Unijuí, 2006. p. 213-238.

GOLDMANN, L. C. Ciências humanas e filosofia. 4. ed. Rio de Janeiro: Bertrand Brasil, 1974.

KUHN, T. A estrutura das revoluções científicas. São Paulo: Perspectiva, 1975.

MALDANER, O. A. Situações de estudo no ensino médio: nova compreensão de educação básica. In: NARDI, R. (Org.). Pesquisa em ensino de ciências no Brasil: alguns recortes. São Paulo: Escrituras, 2007a. p. 237-253.

Ar atmosférico: uma porção do mundo material sobre a qual se deve pensar. In: FRISON, M. D. (Org.). Programa de melhoria e expansão do ensino médio: curso de capacitação de professores da área de ciências da natureza, matemática e suas tecnologias. Ijuí: Editora Unijuí, 2007b. p. 18-46.

MALDANER, O. A. et al. Situação de Estudo como possibilidade concreta de ações coletivas interdisciplinares no ensino médio: ar atmosférico. In: ENCONTRO NACIONAL DE PESQUISA EM EDUCAÇÃO EM CIÊNCIAS, 3., 2001, Atibaia. Anais... São Paulo: ABRAPEC, 2001.

MALDANER, O. A.; ZANON, L. B. Situação de Estudo: uma organização de ensino que extrapola a formação disciplinar em ciências. In: MORAES, R.; MANCUSO, R. (Org.).

Educação em ciências: produção de currículos e formação de professores. Ijuí: Editora Unijuí, 2004. p. 43-64.

MORTIMER, E. F. Construtivismo, mudança conceitual e ensino de ciências: para onde vamos? Investigações em Ensino de Ciências, Porto Alegre, v. 1, n. 1, p. 20-39, 1996. Disponível em: < http://www.if.ufrgs.br/ienci/artigos/Artigo_ID8/v1_n1_a2.pdf>. Acesso em: 13/10/2008.

Linguagem e formação de conceitos no ensino de ciências. Belo Horizonte: Ed. da UFMG, 2000.

MORTIMER, E. F.; SCOTT, P. Atividade discursiva nas aulas de ciências: uma ferramenta sociocultural para analisar e planejar o ensino. Investigações em Ensino de Ciências, Porto Alegre, v. 7, n. 3, p. 283-306, 2002. Disponível em: <http://www.if.ufrgs.br/ienci/ artigos/Artigo_ID94/v7_n3_a2002.pdf>. Acesso em:13/10/2008. 
MORTIMER, E. F.; MACHADO, A. H.; ROMANELLI, L. I. A proposta curricular de química do estado de Minas Gerais. Química Nova, São Paulo, v. 23, n. 2, p. 273-283, 2000 .

PERNAMBUCO, M. M. C. A. Educação e escola como movimento do ensino de ciências: a transformação da escola pública. 1994. 2 v. Tese (Doutorado em Educação) Faculdade de Educação, Universidade de São Paulo, São Paulo, 1994.

PONTUSCHKA, N. (Org.). Ousadia no diálogo: interdisciplinaridade na escola pública. São Paulo: Loyola, 1993.

RIBEIRO, R. M. L.; MARTINS, I. O potencial das narrativas como recurso para o ensino de ciências: uma análise em livros didáticos de Física. Ciência \& Educação, Bauru, v. 13, p. 293-309, 2007.

SANTOS, W. L. P. Educação científica humanista em uma perspectiva freireana: resgatando a função do ensino de CTS. Alexandria: revista de educação em ciência e tecnologia, Florianópolis, v. 1, n. 1, p. 109-131, mar. 2008. Disponível em: <http:// www.ppgect.ufsc.br/alexandriarevista/numero_1/artigos/WILDSON.pdf $>$. Acesso em: 05/06/2009.

SCHROEDER, E. Teoria histórico-cultural do desenvolvimento como referencial para análise de um processo de ensino: a construção dos conceitos científicos em aulas de ciências no estudo da sexualidade humana. 2008. 388 f. Tese (Doutorado em Educação Científica e Tecnológica), Universidade Federal de Santa Catarina, Florianópolis, 2008.

SILVA, A. F. G. da. A construção do currículo na perspectiva popular crítica: das falas significativas às práticas contextualizadas. 2004. 405 p. Tese (Doutorado em Educação) Pontifícia Universidade Católica, São Paulo, 2004.

SNYDERS, G. A. Alegria na escola. São Paulo: Manole, 1988.

VYGOTSKY, L. S. A construção do pensamento e da linguagem. São Paulo: Martins Fontes, 2001.

Pensamento e linguagem. 3. ed. São Paulo: Martins Fontes, 2005.

ZYLBERSZTAJN, A.; CRUZ, S. S. O enfoque ciência, tecnologia e sociedade e a aprendizagem centrada em eventos. In: PIETROCOLA, M. (Org.). Ensino de física: conteúdo, metodologia e epistemologia numa concepção integradora. Florianópolis: UFSC, 2001. p. 171-196. 
ANEXO 1. Texto extraído de Ar Atmosférico (MALDANER, 2007b, p. 27-28)

Outro problema mais sério, associado ao lançamento de um tipo de solvente orgânico na atmosfera, os clorofluorcarbonetos (CFCs), é o depauperamento da camada de ozônio ou a destruição do ozônio estratosférico'. Nessa região da atmosfera acontece o ciclo de formação de destruição do ozônio, pela interação com a radiação UV. Mesmo na estratosfera, os componentes atmosféricos mais abundantes continuam sendo oxigênio e nitrogênio, mas a concentração de ozônio, nessa região da atmosfera, é relativamente mais abundante, daí denominar-se "camada de ozônio". A formação do ozônio acontece, também, a partir do oxigênio molecular, $\mathrm{O}_{2}$, quando raios UV com suficiente energia, hí, decompõe uma molécula de $\mathrm{O}_{2}$ em dois átomos de oxigênio, o chamado oxigênio atômico, $\mathrm{O}$. Este átomo colide com oxigênio molecular formando $\mathrm{O}_{3}$. As equações químicas representativas dessa seqüência de transformações é dada a seguir:

$$
\begin{gathered}
\mathrm{O}_{2}+\mathrm{hv} \rightarrow \mathrm{O}+\mathrm{O} \\
\mathrm{O}+\mathrm{O}_{2} \rightarrow \mathrm{O}_{3}
\end{gathered}
$$

Sabe-se que a atmosfera primitiva não continha oxigênio molecular. Portanto, a camada de ozônio é um fenômeno relativamente recente, em torno de 600 milhões de anos, época em que surgem os primeiros organismos vivos capazes de fotossíntese (vegetais). O subproduto da fotossíntese é $\mathrm{O}_{2}$. Esta molécula, ao absorver radiação UV de alta energia, produz o oxigênio atômico, permitindo a produção do ozônio, conforme representado acima pelas equações químicas.

Na estratosfera, região da camada de ozônio, a radiação UV-B, de comprimento de onda $\lambda$ (280-320 nm), é absorvida pelo $\mathrm{O}_{3}$, exatamente a radiação contra a qual os seres vivos não têm proteção. Ou seja, os organismos vivos desenvolveram-se na ausência dessa radiação, contra ela não têm defesas. Portanto, um aumento de radiação UV-B sobre a superfície terrestre, pela destruição da camada de ozônio, acarretaria sérios prejuízos para a vida na Terra. A destruição do ozônio acontece por ação direta do homem ao lançar na atmosfera gases que reagem com ozônio, diminuindo a sua concentração. Isso dá-se em reação em cadeia, com participação de moléculas de CFCs e óxidos de nitrogênio. Uma reação em cadeia produz em cada etapa de reação uma espécie ativa que reage com novas moléculas de ozônio, acelerando a sua destruição. Nesse processo participa o cloro atômico (Cl), gerado na estratosfera pelas radiações UV, em reação química denominada fotólise. $\mathrm{Na}$ fotólise, átomos de cloro, $\mathrm{Cl}$, são liberados. Estes reagem com ozônio, $\mathrm{O}_{3}$, produzindo $\mathrm{CIO}$ (monóxido de cloro) e $\mathrm{O}_{2}$. Monóxido de cloro reage com oxigênio atômico, presente na formação de ozônio como visto antes, produzindo oxigênio e cloro atômico novamente. $\mathrm{O}$ ciclo se repete indefinidamente, podendo um átomo de cloro destruir milhares de moléculas de $\mathrm{O}_{3}$. Essa reação, em que uma espécie é sempre regenerada em alguma etapa de um ciclo, é denominada reação catalisada ${ }^{2}$. O ciclo pode ser apresentado, segundo linguagem química:

$$
\begin{gathered}
\mathrm{CFCs}+\mathrm{hv} \rightarrow \mathrm{Cl} \\
\mathrm{Cl}+\mathrm{O}_{3} \rightarrow \mathrm{ClO}+\mathrm{O}_{2} \\
\mathrm{ClO}+\mathrm{O} \rightarrow \mathrm{O}_{2}+\mathrm{Cl} \\
\text { O resultado líquido é: } \mathrm{O}_{3}+\mathrm{O} \rightarrow 2 \mathrm{O}_{2}
\end{gathered}
$$

Analisando a seqüência de reações percebe-se a necessidade da presença de oxigênio atômico em concentração adequada. Isso nem sempre ocorre, principalmente na região da Antártica, onde sabemos que está o "buraco" na camada de ozônio. Nessa região da estratosfera o ciclo de regeneração do cloro atômico acontece por interação entre duas moléculas de monóxido de cloro:

${ }^{1}$ Ver em "O Azul do Planeta, um retrato da atmosfera terrestre". Mario Tolentino; Romeu c. Rocha-Filho; Roberto Ribeiro da Silva. Editora Moderna. Col Polêmica, 1997.

2 Para ler mais: QNEsc, n.2, 1995: "Camada de ozônio dá Nobel". Romeu C. Rocha-Filho. 
Gehlen, S. T.; Maldaner, O. A.; Delizoicov, D.

$$
\begin{gathered}
2\left(\mathrm{Cl}+\mathrm{O}_{3} \rightarrow \mathrm{ClO}+\mathrm{O}_{2}\right) \\
\mathrm{ClO}+\mathrm{ClO} \rightarrow \mathrm{Cl}_{2} \mathrm{O}_{2} \\
\mathrm{Cl}_{2} \mathrm{O}_{2}+\mathrm{hv} \rightarrow \mathrm{Cl}+\mathrm{ClO}_{2} \\
\mathrm{ClO}_{2} \rightarrow \mathrm{Cl}+\mathrm{O}_{2} \\
\text { O resultado líquido é: } 2 \mathrm{O}_{3}+\mathrm{hv} \rightarrow 3 \mathrm{O}_{2}
\end{gathered}
$$

Diante desse grave problema de destruição da camada de ozônio por ação direta da ação humana, o conhecimento hoje disponível permite ações conscientes contra o que vem acontecendo. Para participar do debate que se trava no mundo todo é necessário informar-se. Este convite vale para todos. Há muitas informações disponíveis. Deve-se buscá-las e transformá-las em ações!

Artigo recebido em 12/08/2011. Aceito em 2401/2012. 